\title{
Experience in managing patients with coronavirus infection based on the results of the American- Kazakhstan conference
}

\author{
Abay Baigenzhin, Temirlan Karibekov, Elmira Chuvakova, Saule Kushenova, Vladimir Dikolayev, Ainura \\ Doszhan, Askar Kadylbek \\ National Scientific Medical Center, Nur-Sultan, Republic of Kazakhstan
}

Received: 2020-11-15.

Accepted: 2020-11-21

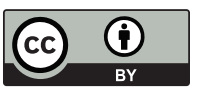

This work is licensed under Creative Commons Attribution 4.0 International License

J Clin Med Kaz 2020; 6(60):99-100

\section{Abstract}

National scientific medical center was able to share experience in the field of treatment strategies and organizational activities of COVID-19 within the framework of the Kazakh-American cooperation, held in the format of the online conference "Current issues of diagnosis and treatment of COVID-19». It has been concluded that treatment strategy and organization measurements, employed during pandemy were relevant and met all the regulatory standards adopted in the world.

Key words: COVID-19, pandemy, treatment strategy, organization measures

Corresponding author:

Vladimir Dikolayev.

E-mail: dikolayevv@mail.ru;

\section{Introduction}

The outbreak of coronavirus infection was unprecedented in its spread and impact on ordinary people's lives. Emerging news were reporting about the new type of virus, originated from the city Wuhan, the capital of Hubei province, China. The new type of virus COVID-19 has reached European countries, affecting most of all Italy, Spain and then moved to the USA, with the number of confirmed new cases currently increasing every day [1]. The first wave of the COVID-19 showed weak sides of the health care systems in all over the world. The World Health Organization has declared the spread of COVID-19 as a pandemy. Currently we are facing the second wave of the COVID-19 outbreak. Additionally to all the quarantine measures which had been taken in all countries, health workers are facing in majority with infected complicated cases. Each country has own experience related to quarantine measures and treatment strategies. We were able to share our experience in the field of treatment strategies and organizational activities within the framework of the Kazakh-American cooperation, held in the format of online conference «Topical issues of COVID-19 diagnosis and treatment».

Kazakhstan was a part of on-going pandemy. As a result of this restrictions in order to contain the spread of
Covid-19 were made by government. New hospitals for infected patients were built in major cities. Because of great number of infected patients some medical centers were converted in to infectious hospitals [2].

The National Scientific Medical Center as a multidisciplinary clinic was also converted in to infectious hospital in order to increase the capacity of serving beds. All medical staff was preliminary educated and informed with the new guideline (10th revision) which was adopted by the Ministry of Healthcare. Oxygen supply and all necessary equipment were prepared. Due to sanitary rules in each department of the center quarantine zone was delineated. Each department was divided in to «clean» and «dirty» zones. Medical staff was instructed and equipped to use personal protective equipment (gowns, protective glasses and gloves) and hand hygiene for every contact with individual. As the patients started to admit body temperature and state of health of the medical staff was every day monitored. Triage of the patients was done in the emergency department. Patients in severe condition were directly transported to the intensive care unit. Other patients in mild and moderate condition were transported to the remaining departments.

Intensive care unit was equipped with 26 intensive care beds, 26 monitors (arterial blood pressure, heart rate, $\mathrm{SpO} 2$, 
temperature, breath rate), 26 Bobrov's apparatus (flowmeter, humidified oxygen supply), 22 ventilators, 1 portable $\mathrm{X}$ - ray machine, $1 \mathrm{CT}$ machine, 1 «24-hour» express laboratory, 1 room for renal replacement therapy with 2 devices for performing renal replacement therapy, 1 blood bank (with sufficient supply of blood components). The treatment in the intensive care unit was set according protocol adopted in Kazakhstan. The treatment included: antibiotics, anticoagulants, desagregant therapy, hormones, gastroprotection, humidified oxygen supply, renal replacement therapy. Mechanical ventilation was set according indications: in case of increase in respiratory failure during CPAP therapy, cardiac arrest due to decompensation of the main disease. In total 723 patients passed through intensive care unit. Among them 549 patients were from other departments receiving CPAP therapy. Remaining 174 patients received (42 mechanical ventilation, 132 NIMV) mechanical ventilation. The mortality rate was 5,8\% (42 patients). 1 patent «The method of the treatment of patients with COVID-19 pneumonia by noninvasive mechanical ventilation» was released.

130 patients with COVID-19 had a treatment in the therapy department. The vast majority of patients, critically ill had concomitant diseases: hypertension, diabetes mellitus, chronic respiratory disease, renal disease and obesity. Most of them could be placed at a higher risk of serious disease. Accordingly, the doctors of the department had to deal not only with the main disease but also with the concomitant. The therapy of patients was consisted of different strategy. The anticoagulant or antiplatelet therapy was prescribed in order to avoid thromboembolic events. In patients with diabetes mellitus the prescription of short-acting insulins, as well as the selection of antihyperglycemic therapy was done. Critical ill patients with acute kidney injury were able to have the renal replacement therapy. Patients with autoimmune rheumatic diseases were treated by hormones such as prednisone. Corticosteroids also were used in the main therapy. New evidences show that the mortality rate was lower among dexamethasone treated patients than control group of patients [3]. In the department the treatment of COVID-19 patients with dexamethasone was as follows $6 \mathrm{mg}$ per day for up to 10 days.

Some patients with concomitant cardiac diseases were triaged to converted cardiology and cardiac surgery departments. 146 COVID-19 patients admitted to cardiology, cardiac surgery departments. The majority of patients had a concomitant congestive heart disease. Current researches stress that patients with heart failure are at higher risk of mortality. It has been proposed that it is due to damaging effect of the cytokine storm on myocardial tissue, causing injury and worsen heart failure [4]. The treatment of the patients was modified according with the concomitant cardiac diseases. In some severe cases clinical features of the patients were associated with pulmonary hypertension.

All treatment strategies and organization measures in conjunction with specialists from the USA were reported and discussed. Despite the high mortality rate in the world, the lack of proper experience and practice of treatment COVID-19 our clinic did not stand aside and became a participant in this event, which resulted in the data provided in our article. It has been concluded that treatment strategy and organization measurements, employed during pandemy were relevant and met all the regulatory standards adopted in the world.

Disclosures: There is no conflict of interest for all authors.

\section{References}

1. Pascarella G, Strumia A, Piliego C, Bruno F, Del Buono R, Costa F et al. COVID-19 diagnosis and management: a comprehensive review. Journal of Internal Medicine. 2020; 288(2):192-206. doi: 10.1111/joim.13091.

2. Zhalmagambetov B, Madikenova M, Paizullayeva S, Abbay A, Gaipov A. COVID-19 Outbreak in Kazakhstan: Current Status and Challenges. Journal of Clinical Medicine of Kazakhstan. 2020; 1(55):6-8. doi: 10.23950/1812-2892-JCMK-00763.

3. Tomazini BM, Maia IM, Bueno FR, Silva MV, Baldassare FP, Costa EL et al. COVID-19-associated ARDS treated with DEXamethasone (CoDEX): study design and rationale for a randomized trial. Revista Brasileirade Terapia Intensiva. 2020; 32(3):354-362.doi: 10.5935/0103-507X.20200063.

4. Long B, Brady WJ, Koyfman A, Gottlieb M. Cardiovascular complications in COVID-19. American Journalof Emergency Medicine. 2020; 38(7):1504-1507. doi: 10.1016/j.ajem.2020.04.048. 